\title{
Fixation of the short-term central venous catheter. A comparison of two techniques ${ }^{1}$
}

Mário Lúcio Marques Leal', Ana Beatriz Alkmim Teixeira Loyola", Alexandre Ciappina Hueb"', José Dias da Silva Neto'v, Marcos Mesquita Filhov, Luiz Francisley de PaivaV', Mauricio Landulfo Jorge GuerrieriVII, João Paulo Nunes Fernandes ${ }^{\mathrm{VIII}}$, Artur Costa Barros ${ }^{\mathrm{IX}}$, Lydia Masako Ferreira ${ }^{\mathrm{X}}$

'Fellow Master degree, Professional Master's Program in Applied Health Sciences, Universidade do Vale do Sapucaí (UNIVÁS), Pouso Alegre-MG, Brazil. Conception, design, intellectual and scientific content of the study; acquisition, interpretation and analysis of data; manuscript writing.

"PhD, Associate Professor, Professional Master's Program in Applied Health Sciences, UNIVÁS, Pouso Alegre-MG, Brazil. Conception, design, intellectual and scientific content of the study; interpretation and analysis of data; manuscript writing; critical revision; final approval.

II'PhD, Head, Department of Cardiac Surgery, Hospital das Clínicas Samuel Libânio, UNIVÁS, Pouso Alegre-MG, Brazil. Critical revision.

IVPhD, Associate Professor, Professional Master's Program in Applied Health Sciences, UNIVÁS, Pouso Alegre-MG, Brazil. Critical revision.

VPhD, Full Professor, Department of Biostatistics, UNIVÁS, Pouso Alegre-MG, Brazil. Interpretation of data, statistical analysis, critical revision.

V'Biologist, Research Laboratory, UNIVÁS, Pouso Alegre-MG, Brazil. Acquisition of data.

VIIResident, Hospital das Clínicas Samuel Libânio, UNIVÁS, Pouso Alegre-MG, Brazil. Technical procedures, acquisition of data.

VIIIMD, Intensive Care Department, Hospital das Clínicas Samuel Libânio, UNIVÁS, Pouso Alegre-MG, Brazil. Technical procedures, acquisition of data.

${ }^{1 X}$ Graduate student, UNIVÁS, Pouso Alegre-MG, Brazil. Acquisition of data.

xPhD, Chairwoman, Head, Division of Plastic Surgery, Universidade Federal de São Paulo (UNIFESP), Brazil. Critical revision, final approval.

\section{Abstract}

Purpose: To compare the fixation of the central venous catheter (CVC) using two suture techniques.

Methods: A clinical, analytical, interventional, longitudinal, prospective, controlled, singleblind and randomized study in adult, intensive care unit (ICU) patients. After admission and indication of CVC use, the patients were allocated to the Wing group $(n=35$, catheter fixation with clamping wings and retainers) or Shoelace group ( $n=35$, catheter fixation using shoelace cross-tied sutures around the device). Displacement, kinking, fixation failure, hyperemia at the insertion site, purulent secretion, loss of the device, psychomotor agitation, mental confusion, and bacterial growth at the insertion site were evaluated.

Results: Compared with the Wing group, the Shoelace group had a lower occurrence of catheter displacement ( $n=0$ versus $n=4 ; p=0.04$ ), kinking ( $n=0$ versus $n=8 ; p=0.001$ ), and fixation failure ( $n=2$ versus $n=8 ; p=0.018)$. No significant difference was found in bacterial growth ( $n=20$ versus $n=14 ; p=0.267$ ) between groups.

Conclusion: The Shoelace fixation technique presented fewer adverse events than the Wing fixation technique.

Key words: Catheters. Vascular Access Devices. Suture Techniques. Microbiota. Blood Circulation. 


\section{Introduction}

The short-term central venous catheter (CVC) is placed in large venous vessels for the administration of solutions into the superior vena cava or right atrium. It is designed for continuous use in patients hospitalized for days or weeks ${ }^{1}$. CVC is mainly indicated for patients with difficult access to peripheral veins, delivery of intravenous chemotherapy, potentially sclerosing medications, and total parenteral nutrition, repeated administration of blood products or blood components, repeated collection of blood samples, and hemodynamic monitoring ${ }^{2,3}$.

The CVC is inserted by percutaneous puncture and has been associated with a number of complications ${ }^{2}$. The level of physician experience of more than 50 punctures performed reduces complication risk ${ }^{4,5}$. The CVC is placed using the Seldinger technique, in which the vessel is punctured with a long needle, whereby a guidewire is advanced to the appropriate position for subsequent insertion and positioning of the catheter ${ }^{2,6}$.

According to the American Society of Anesthesiologists (ASA) task force on central venous access, the use of sutures is the preferred CVC fixation technique to minimize the risk of infection, but the use of sutures, clamps or tapes for CVC fixation is based on local or institutional practices ${ }^{7}$.

The CVC insertion site in adults should be based on clinical needs and located in an uncontaminated area, preferably at the upper end of the body to minimize the risk of infection ${ }^{7}$. Catheter-related bloodstream infections occur by migration of the skin microbiota through the percutaneous insertion site, suggesting that sutureless securement devices may prevent lesions around the insertion site, thus reducing bacterial colonization ${ }^{8}$. The use of chlorhexidine is recommended for hand antisepsis prior to venipuncture and dressing changes ${ }^{7}$. The costs of catheter-related complications are high. A single catheter-related infection costs from US\$4.000 to US\$56.000 and complications resulting from inadequate positioning may affect the reimbursement rates of medical centers ${ }^{9}$.

Unplanned removal of the CVC and the need for reinsertion has received little attention, but carries a potential lifethreatening risk ${ }^{10}$. CVC should be fixed to the skin and should not move into or out of large veins, as this may lead to failure of the venous line, causing support interruption (i.e., delivery of inotropic drugs and vasopressors) and hemorrhagic shock ${ }^{11}$. The risk of unplanned removal of the CVC is greater in patients with agitation and delirium ${ }^{12}$.

The literature on CVC remains inconclusive whether the most appropriate method of CVC fixation is the use of devices based on suture securement, which are available as cormercial kits, or the use of sutureless securement devices, which are more expensive and not available in public health services. The present study addressed this problem and evaluated two CVC fixation techniques used in two hospitals in Southern Minas Gerais (Brazil), where the procedures are not standardized.

\section{Methods}

The study was approved by the Research Ethics Committee of UNIVÁS (approval no. 1.372.730) and performed in accordance with the Resolution 466/2012 of the Brazilian National Health Council (CNS) on research involving human beings. Written informed consent was obtained from all patients or their representatives prior to their inclusion in the study, and anonymity was assured.

This clinical, analytical, interventional, 
longitudinal, prospective, controlled, singleblind, randomized trial was conducted from January to August 2016 in adult clinical and surgical intensive care units (ICUs) of the Samuel Libânio General Hospital at the Universidade do Vale do Sapucaí (UNIVÁS) and ICUs of the Santa Paula Hospital and Maternity Center, both located in Pouso Alegre-MG, Brazil.

A pilot study with 14 patients with short-term CVC was conducted to define the size of the sample. Adverse events were evaluated and loss of catheter fixation to the skin was used as the primary endpoint. The Fleiss method with continuity correction was applied to determine the sample size, assuming a sample size ratio of 1.0, percentage of positive non-exposed patients of $50.0 \%$ (Wing fixation), and percentage of positive exposed patients of $14.0 \%$ (Shoelace cross-tied fixation). Participants were selected by simple random sampling. Setting the significance level $\alpha$ at $0.05(5 \%)$ and the power of the sample $(1-\beta)$ at $80 \%$, the sample size of 62 participants (31 patients per group) would be required to detect differences between groups. Anticipating some missing data, 35 patients were randomly allocated to each group, for a total of 70 patients.

Adult patients of both sexes, with indication for CVC insertion into jugular or subclavian veins, admitted to an ICU in the participating institutions were selected to participate in the study.

Exclusion criteria were break in asepsis during the placement of the device; multiple puncture attempts (i.e., more than 3 puncture sites in the chosen access route) resulting in excessive local trauma; need for device repositioning due to an anomalous route or catheter malpositioning after insertion, verified by chest radiography; CVC removal before the minimum period of three days; and patient death before the minimum period of three days.

\section{Randomization}

The allocation sequence was generated using a computer-generated randomization chart (htpp://www.randomization.com). The patients were randomly allocated to 2 groups: the Wing group ( $n=35$, catheter fixation with clamping wings and retainers) and Shoelace group ( $n=35$, catheter fixation using shoelace cross-tied sutures around the device).

\section{Procedure}

The team responsible for CVC insertions was composed of three physicians with training and experience of more than 50 punctures using the Seldinger technique ${ }^{13}$.

The physician, already wearing a mask and a cap, performed hand wash with $4 \%$ chlorhexidine solution with surfactants (a skin degerming agent) and dressed the sterilized gown and gloves to perform antisepsis of the patient's skin?. A Foerster clamp and sterile gauze were used for applying a $4 \%$ chlorhexidine solution from the puncture site to the opposite direction, repeating the procedure three times and then removing the excess solution. Next, $0.5 \%$ alcoholic chlorhexidine was also applied three times from the puncture site to the opposite direction using a Foerster clamp and sterile gauze. Fenestrated areas were positioned to ensure a sterile barrier. Before the catheter puncture was performed, a minimum of 2 minutes was allowed to elapse after application of the antiseptic to the skin ${ }^{8}$.

The Seldinger technique was used for the percutaneous puncture of central venous vessels, including internal jugular veins and subclavian veins. The catheter used was the Arrow double-lumen 7Fr $20 \mathrm{~cm}$ CVC (Arrow International Inc, Cleveland, OH). After the puncture and catheter insertion, the device was secured to the skin with a 3-0 nylon thread. Catheter fixation was performed according to group allocation, using either the Wing or 
Shoelace fixation technique, as described below.

\section{Wing fixation technique}

The catheter was fixed to the skin with a single stitch and triple knots were tied to each perforation lateral to the securing wings (rubber clamp and retainer), leaving a distance of $2 \mathrm{~cm}$ between the securing wings and puncture site for visualization of the ostium. The catheter was fixed to the skin with a single stitch and triple knots were tied to each perforation of the distal wings (Figure 1).

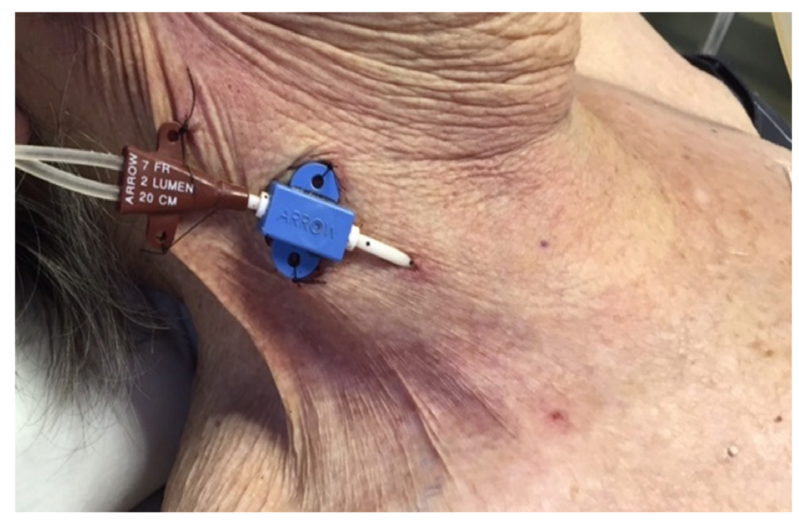

Figure 1 - Wing fixation of a short-term CVC with securing wings in an ICU patient.

\section{Shoelace fixation technique}

The catheter was first fixed to the skin with a U-shaped stitch placed around the puncture site, cross-tied with stitches known as "shoelace sutures" until the threads passed through the perorations of the distal wings, and secured with triple knots. Next, the catheter was secured to the skin with a single stitch and triple knots were tied to each perforation of the securing wings, leaving a distance of $2 \mathrm{~cm}$ between the securing wings and puncture site for visualization of the ostium (Figure 2 ).

Gauze and micropore tape dressings were applied ${ }^{14}$ and $0.5 \%$ alcoholic chlorhexidine solution was used to clean the insertion site during daily dressing changes ${ }^{8}$.

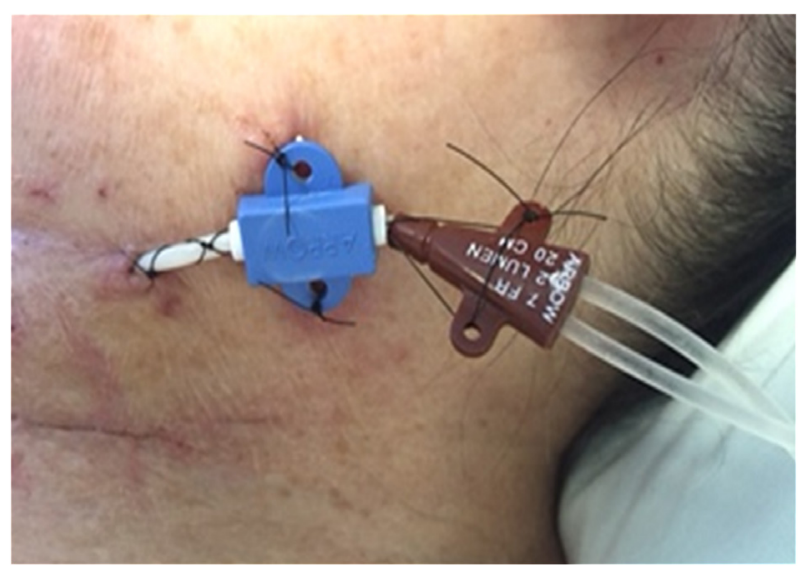

Figure 2 - Shoelace fixation of a short-term CVC with securing wings in an ICU patient.

\section{Data collection}

Data were collected 3 and 5 days after CVC insertion, immediately before the daily dressing change. ICU nurses on duty, with more than 5 years of experience, completed a standardized data collection form. The presence of adverse events related to catheter fixation was indicated with an " $X$ " in the form, according to the following items:

1. Catheter displacement - defined as the displacement of the device of more than $2 \mathrm{~cm}$ due to tensile forces, measured by a graduated scale on the catheter (Figure $3 \mathrm{~A}$ ).

2. Catheter kinking - folding of the catheter on itself (Figure 3B).

3. Loss of fixation - loss of sutures that held the catheter in place (Figure $3 \mathrm{C}$ ).

4. Hyperemia at the insertion site redness around the ostium (Figure 3D).

5. Purulent-looking secretion presence of a yellowish, thick secretion at the insertion site (Figure 3D).

6. Loss of device - "pulling out" of the catheter or damaging one of the lumens of the device by traction (Figure 3F). 
7. Psychomotor agitation presence of involuntary and purposeless movements associated or not with aggressive behavior ${ }^{15}$.

8. Mental confusion (delirium) disturbance of consciousness characterized by acute onset and fluctuating course of inattention, accompanied by change in cognition or perceptual disturbance ${ }^{16}$.
Disease severity was assessed using APACHE II, a severity of disease classification system $^{17}$. APACHE II uses a point score based on 12 routine physiologic measurements, age, and previous health status to provide a general measure of disease severity. An increasing score (range 0-71) is associated with increased risk of hospital death.

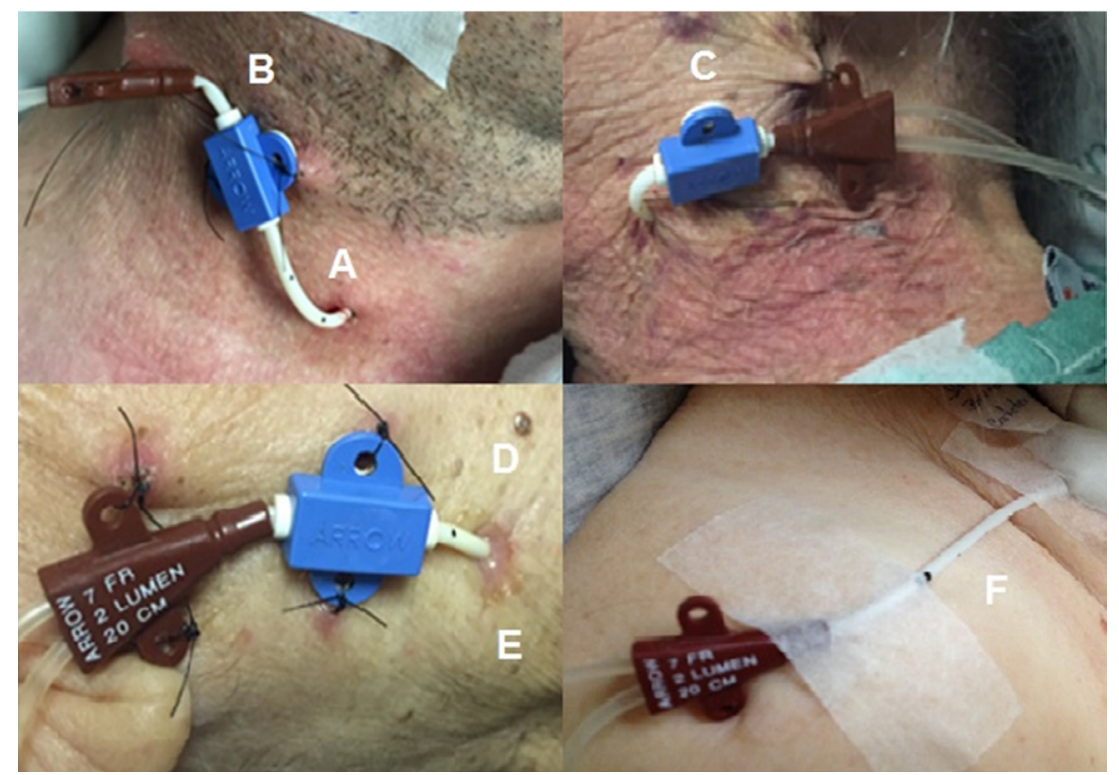

Figure 3 - Examples of adverse events observed in ICU patients associated with the use of a short-term CVC. Catheter displacement (A); Catheter kinking (B); Loss of fixation (C); Hyperemia at insertion site (D); Purulentlooking secretion (E); Loss of the device (F).

\section{Evaluation of the microbiological culture}

After completing the data collection form, samples were collected at the catheter insertion site for microbiological culture. Sample collection was performed 3 and 5 days after CVC insertion, before dressing changes, using sterile and disposable swabs packaged in individual swab containers (Absorve ${ }^{\circ}$, Carl, São Paulo, Brazil). The swab was previously moistened in a sterile phosphate-buffered saline (PBS buffer) containing 3\% Tween-8018, and rubbed for 30 seconds with uniform up and down movements in a $5 \mathrm{~cm}^{2}$ area delineated by a sterile filter paper template (Nalgon ${ }^{\circ}$, Nalgon Equipamentos Científicos Ltda, São Paulo, Brazil) ${ }^{19}$. The swab was then placed in sterile tubes containing $1 \mathrm{ml}$ of $0.9 \%$ saline solution and 8 glass beads, and transported in a thermal box to the Laboratory of Basic Research of the School of Health Sciences at UNIVÁS.

To count the isolated microorganisms, $0.1 \mathrm{ml}$ of the obtained material was placed in Petri dishes with plate count agar (PCA) and spread with a sterile Drigalski spatula. The plates were incubated at $35^{\circ} \mathrm{C}$ for 24 hours and the colonies were counted. 


\section{Statistical analysis}

Descriptive analysis was conducted to determine the central tendency (means and medians) and standard deviation (SD) for quantitative variables; proportions were used for categorical variables. Categorical variables were compared using the Chi-square test. Normal distribution was investigated using the Kolmogorov-Smirnov test. A $t$-test was used for comparing data with parametric distribution. Data that were not normally distributed were compared using the Mann-Whitney $U$ test.

Statistical analysis was carried out using the Predictive Analytics Software (PASW) 18.0 for Windows (IBM Corp., Armonk, NY, USA) and the Microsoft Office Excel software (Microsoft Corp., Redmond, WA, USA).

All statistical tests were performed at a significance level $\alpha$ of $0.05(p<0.05)$. Data were expressed as mean \pm SD.

\section{Results}

Of the 70 patients recruited from January to August 2016, 67 of them agreed to participate in the study, 2 were excluded because of catheter malpositioning, 2 patients died and an elective removal of the device occurred before the minimum period of 3 days.

Considering 2 accidental CVC losses, 60 patients were evaluated for catheter displacement, kinking, loss of fixation, hyperemia at the insertion site, purulent secretion, and loss of the device, and 62 patients were assessed for psychomotor agitation and mental confusion on the day- 3 assessment. On the day- 5 assessment, 2 more accidental losses and one elective removal of the device had occurred, and 3 patients had died, resulting in a sample of 54 patients; for the items psychomotor agitation and mental confusion, 55 patients were evaluated. Considering patient deaths, CVC losses, elective removals and accidental losses of collected samples, 57 cultures were evaluated for day 3 and 53 cultures were evaluated for day 5 .
The mean age of patients was $59.8 \pm$ 18.6 years in the Shoelace group $(n=32)$ and $61.1 \pm 20.8$ years in the Wing group $(n=30)$, with no significant difference between groups $(p=0.803)$. No significant difference in gender distribution $(p=0.640)$ was found between groups (Figure 4).

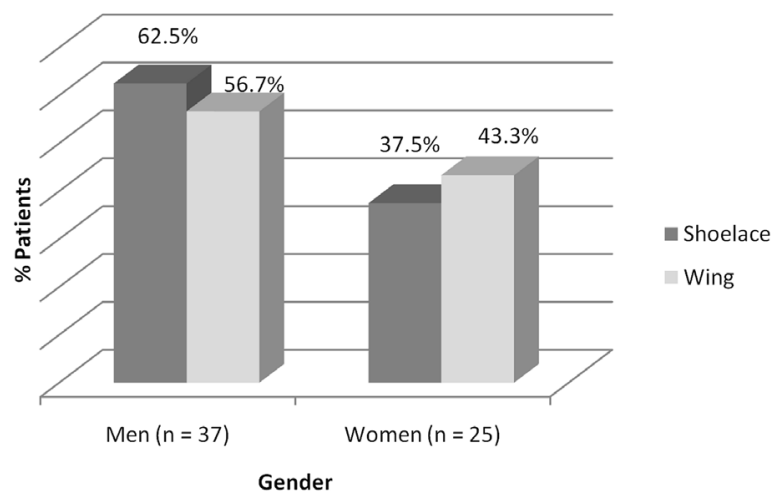

Figure 4 - Frequency distribution by gender of ICU patients with short-term CVC, according to the fixation technique. Chi-square test, $p=0.640$.

The mean disease severity score for the whole sample $(n=62)$ was $19.89 \pm 5.90$. For the Shoelace group $(n=32)$, the mean score was $19.81 \pm 5.214$ (median, 20.0) and for the Wing group $(n=30)$, the mean score was $19.97 \pm$ 6.651 (median, 18.0). The groups were similar $(p=0.919)$, showing no significant difference in disease severity.

The subjective assessment of mental status was also performed and showed no significant difference between groups on day 3 and (Table 1) and day 5 (Table 2).

Table 1 - Frequency distribution of the mental state (agitation and confusion) of ICU patients with CVC on day 3 for both groups.

\begin{tabular}{lrlll}
$\begin{array}{l}\text { Mental } \\
\text { State }\end{array}$ & & $\begin{array}{l}\text { Shoelace } \\
\text { group }\end{array}$ & $\begin{array}{l}\text { Wing } \\
\text { group }\end{array}$ & p-value* \\
\hline Agitation & $\mathrm{N}$ & 6.0 & 5.0 & 0.830 \\
& $\%$ & $18.8 \%$ & $16.7 \%$ & \\
Mental & $\mathrm{N}$ & 8.0 & 4.0 & 0.245 \\
confusion & & & & \\
& $\%$ & $25 \%$ & $13.3 \%$ & \\
\hline
\end{tabular}

*Chi-square test $(p<0.05)$. 
Table 2 - Frequency distribution of the mental state (agitation and confusion) of ICU patients with CVC on day 5 for both groups.

\begin{tabular}{lllll}
$\begin{array}{l}\text { Mental } \\
\text { State }\end{array}$ & & $\begin{array}{l}\text { Shoelace } \\
\text { group }\end{array}$ & $\begin{array}{l}\text { Wing } \\
\text { group }\end{array}$ & p-value* \\
\hline Agitation & N & 6.0 & 5.0 & 0.893 \\
& $\%$ & $20.7 \%$ & $19.2 \%$ & \\
Mental & $\mathrm{N}$ & 8.0 & 6.0 & 0.702 \\
$\begin{array}{l}\text { confusion } \\
\end{array}$ & & & & \\
& $\%$ & $27.6 \%$ & $23.1 \%$ & \\
\hline
\end{tabular}

${ }^{*}$ Chi-square test $(p<0.05)$.

The subclavian vein was used in 15 (24.2\%) patients, with the Shoelace technique being used in 6 (9.68\%) of them and the Wing technique, in 9 (14.52\%). The internal jugular vein was used in 47 patients (75.8\%), with the Shoelace technique being used in 26 (41.94\%) of them and the Wing technique, in 21 (33.87\%). There was no significant difference $(p=0.301)$ in the distribution of the access vein between the two techniques.

Overall, adverse events occurred in $45.16 \%$ of cases. Adverse events in general occurred in $8(25 \%)$ patients in the Shoelace group compared to $20(66.7 \%)$ patients in the Wing group (Table 3 ).

Table 3 - Frequency distribution of adverse events in general related to catheter insertion in ICU patients with CVC on day 5 for both groups.

\begin{tabular}{lllll} 
Technique & \multicolumn{4}{l}{ Adverse Events } \\
& & No & Yes & Total \\
\hline Shoelace & N & 24 & 8 & 32 \\
& $\%$ & $75 \%$ & $25 \%$ & $100 \%$ \\
\multirow{2}{*}{ Wing } & $\mathrm{N}$ & 10 & 20 & 30 \\
& $\%$ & $33.30 \%$ & $66.70 \%$ & $100 \%$ \\
Total & $\mathrm{N}$ & 34 & 28 & 62 \\
& $\%$ & $54.84 \%$ & $45.16 \%$ & $100 \%$ \\
\hline
\end{tabular}

Chi-square test, $p=0.001$.
The occurrence of the different types of adverse events during the study period was compared between both techniques. On day 3 , a significant difference between groups was found only for catheter kinking (Table 4). On day 5 , significant differences between groups were found for catheter displacement, kinking and loss of fixation (Table 5). No significant differences were observed in loss of device, hyperemia and purulent-looking secretion at insertion site on day 3 (Table 4 ) and day 5 (Table 5) between groups.

Table 4 - Frequency distribution of adverse events in ICU patients with CVC on day 3, according to the fixation technique used.

\begin{tabular}{|c|c|c|c|c|}
\hline $\begin{array}{l}\text { Adverse } \\
\text { Events }\end{array}$ & & $\begin{array}{l}\text { Shoelace } \\
\text { group }\end{array}$ & $\begin{array}{l}\text { Wing } \\
\text { group }\end{array}$ & p-value* \\
\hline \multirow[t]{2}{*}{$\begin{array}{l}\text { Displacement } \\
>2 \mathrm{~cm}\end{array}$} & $N$ & 0 & 2 & 0.214 \\
\hline & $\%$ & $0 \%$ & $7.1 \%$ & \\
\hline \multirow[t]{2}{*}{ Kinking } & $N$ & 0 & 4 & 0.042 \\
\hline & $\%$ & $0 \%$ & $14.3 \%$ & \\
\hline \multirow[t]{2}{*}{$\begin{array}{l}\text { Loss of } \\
\text { fixation }\end{array}$} & $N$ & 2 & 6 & 0.130 \\
\hline & $\%$ & $6.3 \%$ & $21.4 \%$ & \\
\hline \multirow[t]{2}{*}{$\begin{array}{l}\text { Los of } \\
\text { device }\end{array}$} & $N$ & 0 & 2.0 & 0.230 \\
\hline & $\%$ & $0 \%$ & $6.7 \%$ & \\
\hline \multirow[t]{2}{*}{ Hyperemia } & $N$ & 3 & 3 & 1.0 \\
\hline & $\%$ & $9.4 \%$ & $10.7 \%$ & \\
\hline \multirow[t]{2}{*}{$\begin{array}{l}\text { Purulent } \\
\text { secretion }\end{array}$} & $N$ & 1 & 1 & 1.0 \\
\hline & $\%$ & $3.1 \%$ & $3.6 \%$ & \\
\hline
\end{tabular}


Table 5 - Frequency distribution of adverse events in ICU patients with CVC on day 5, according to the fixation technique used.

\begin{tabular}{lllll}
$\begin{array}{l}\text { Adverse } \\
\text { Events }\end{array}$ & & $\begin{array}{l}\text { Shoelace } \\
\text { group }\end{array}$ & $\begin{array}{l}\text { Wing } \\
\text { group }\end{array}$ & p-value \\
$\begin{array}{l}\text { Displacement } \\
>2 \mathrm{~cm}\end{array}$ & $\mathrm{~N}$ & 0 & 4 & $\mathbf{0 . 0 4}$ \\
& $\%$ & $0 \%$ & $16 \%$ & \\
Kinking & $\mathrm{N}$ & 0 & 8 & $\mathbf{0 . 0 0 1}$ \\
& $\%$ & $0 \%$ & $32 \%$ & \\
Loss of fixation & $\mathrm{N}$ & 2 & 8 & $\mathbf{0 . 0 1 8}$ \\
& $\%$ & $6.9 \%$ & $32 \%$ & \\
Los of device & $\mathrm{N}$ & 1 & 3 & $0.344^{*}$ \\
& $\%$ & $3.3 \%$ & $10.7 \%$ & \\
Hyperemia & $\mathrm{N}$ & 4 & 5 & $0.718^{*}$ \\
& $\%$ & $13.8 \%$ & $20 \%$ & \\
Purulent & $\mathrm{N}$ & 0 & & \\
secretion & $\%$ & $0 \%$ & $4 \%$ & $0.463^{*}$ \\
& & & 1 & \\
\hline
\end{tabular}

*Fisher's exact test $(p<0.05) ;{ }^{* *}$ Chi-square test $(p<0.05)$; Numbers in bold indicate statistical significance.

The microbiological analysis of samples collected at the insertion site on day 3 (Figure 5) and day 5 (Figure 6) showed no significant differences between groups.

No significant difference was found in bacterial count in samples collected at the catheter insertion site on days 3 and 5 of the study period (Table 6).

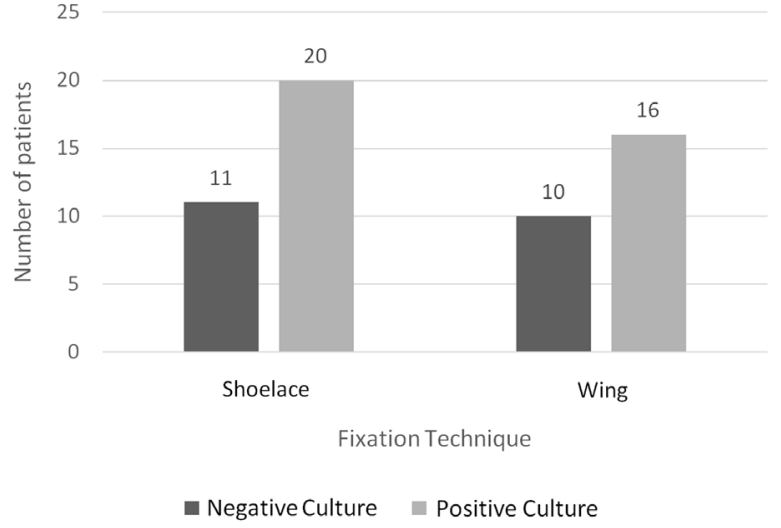

Figure 5 - Microbiological analysis of samples collected at the insertion site in ICU patients with CVC on day 3 , according to the fixation technique. Fisher's exact test; $p=1.0$.

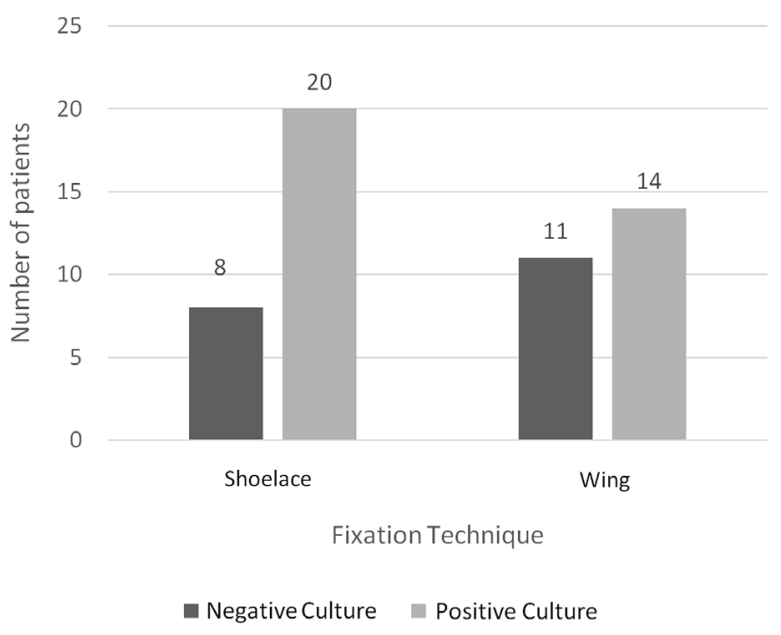

Figure 6 - Microbiological analysis of samples collected at the insertion site in ICU patients with CVC on day 5 , according to the fixation technique. Fisher's exact test; $p=1.0$.

Table 6 - Bacterial count in positive samples collected at the insertion site in ICU patients with CVC on days 3 and 5, according to the fixation technique.

\begin{tabular}{|c|c|c|}
\hline $\begin{array}{l}\text { Fixation } \\
\text { technique }\end{array}$ & $\begin{array}{l}\text { Day } 3 \\
\text { Bacterial } \\
\text { count (CFU/ } \\
\text { ml) }\end{array}$ & $\begin{array}{l}\text { Day } 5 \\
\text { Bacterial } \\
\text { count (CFU/ } \\
\text { ml) }\end{array}$ \\
\hline & Median & IViedian \\
\hline $\begin{array}{l}\text { Shoelace } \\
\text { group }\end{array}$ & 100 & 2250 \\
\hline Wing group & 100 & 100 \\
\hline $\begin{array}{l}\text { Mann-Whitney } \\
\text { test }\end{array}$ & $p=0.792$ & $p=0.129$ \\
\hline
\end{tabular}

$\mathrm{CFU} / \mathrm{ml}$, colony forming units per milliliters.

\section{Discussion}

No study describing the catheter fixation technique using shoelace cross-tied sutures was found in the literature. However, it resembles the Chinese Finger Trap technique described for the fixation of biliary catheters. In this technique, the thread is passed through the skin near to the insertion of the biliary catheter, and the suture ends are tensioned for equal lengths. The suture is then tied around 
the catheter near its insertion point into the skin. The ends of the sutures are crossed around the catheter up to $6 \mathrm{~cm}$ from the insertion point. A triple knot is firmly secured at the distal end of the catheter and the suture ends are crossed over each other several times in the reverse direction on the way back to the skin. The thread is then sutured to the skin next to the catheter ${ }^{20}$.

The fixation technique using securing wings consisted of a rubber clamp and retainer, chosen as the control procedure in the present study, was that recommended by the catheter manufacturer (Arrow International Inc.) and provided with the catheter kit.

The incidence of adverse events in ICUs, semi intensive units and inpatient units of a private tertiary hospital with 250 beds in São Paulo (Brazil) was evaluated in $2006^{21}$. A total of 229 adverse events were reported during a period of 4 months; 21 (9.17\%) of them were associated with the use of CVCs and included obstruction, extravasation, dislodgement, incorrect fixation, unplanned removal, bleeding, and clamping ${ }^{21}$. In the present study, $45.16 \%$ of patients experienced adverse events, including catheter displacement, kinking, loss of fixation and loss of device, what is a high percentage of adverse events associated with CVC compared to the findings of Nascimento et al. ${ }^{21}$.

In the study by Bevc et $a .^{22}$ on hemodialysis catheters, $33.7 \%$ of them were removed because of complications, such as CVC occlusion, decreased blood flow, loss of fixation, displacement, CVC malpositioning, fever, signs of infection, and bleeding at the insertion site ${ }^{26}$. In the present study, a reduced occurrence of catheter displacement, kinking and loss of fixation was obtained with the use of the Shoelace fixation technique.

Jaber et al. $^{23}$ conducted a study describing the incidence, risk factors, and characteristics and consequences of agitation in a mixed clinical-surgical population of critically ill patients. Agitation was associated with an unplanned CVC removal rate of $16 \%$ compared to $1 \%$ in the non-agitaded group ${ }^{23}$. In the present study, $23.1 \%$ of patients in the Wing group showed mental confusion and $19.2 \%$ had agitation on day 5 , resulting in an CVC (unplanned removal) loss rate of $10.7 \%$. In the Shoelace group, $27.6 \%$ patients showed mental confusion and $20.7 \%$ had agitation, corresponding to an unplanned removal rate of $3.3 \%$, but without significant difference between groups.

A previous literature review compared the use of gauze and tape with that of transparent polyurethane dressings to secure CVCs. The use of gauze and tape was associated with lower rates of catheter-related bloodstream infections ${ }^{14}$. In the present study, gauze and micropore tape were chosen for the dressings because of the possibility that the transparent film could interfere with the stability of the catheter. Catheter stabilization is an important intervention that may reduce the risks of phlebitis and catheter displacement, and may also contribute to prevent bloodstream infection ${ }^{8}$. The most common pathway in the pathophysiology of CVC infection is the migration of skin microorganisms from the insertion site through the tunnel created by the insertion of the catheter ${ }^{24}$. The total displacement of the tip of a CVC inserted in a patient during flexion and maximum extension of the head and neck ranges from 1.5 to $3.0 \mathrm{~cm}^{25}$. Thus, it was chosen to assess displacements greater than $2 \mathrm{~cm}$ with the head in a neutral position relative to the thorax.

Sixty catheters were analyzed during a period of 5 months in a previous study evaluating the combination of skin culture with the culture in CVC connectors for stratification of the negative predictive value in catheter colonization and catheter-related bloodstream infection ${ }^{26}$. ICU patients undergoing cardiac surgery were enrolled in the study when the CVC remained for at least 7 days after insertion. Skin and/or needleless connector and/or hub 
cultures were positive in $51.7 \%$ of the samples after removal of the device ${ }^{26}$. In the present study, the skin and catheter complex sample was collected at the CVC insertion site during the study period. The microbiological culture was positive in $64.5 \%$ of the samples on day 3 and in $71.4 \%$ of the samples on day 5 among the patients in the Shoelace group, and in $61.5 \%$ of the samples on day 3 and $56 \%$ of the samples on day 5 among patients in the Wing group, without significant differences between groups.

\section{Conclusion}

The Shoelace fixation technique resulted in fewer adverse events than the Wing fixation technique.

\section{References}

1. Pittiruti $M$, Hamilton $H$, Biffi $R$, MacFie J, Pertkiewicz $M$; ESPEN. ESPEN Guidelines on parenteral nutrition: central venous catheters (access, care, diagnosis and therapy of complications). Clin Nutr. 2009 Aug;28(4):365-77. doi: 10.1016/j. clnu.2009.03.015.

2. Araújo S. Acessos venosos centrais e arteriais periféricos: aspectos técnicos e práticos. Rev Bras Ter Intensiva. 2003 AprJun;15(2):70-82.

3. Bishop L, Dougherty L, Bodenham A, Mansi J, Crowe P, Kibbler C, Shannon M, Treleaven J. Guidelines on the insertion and management of central venous access devices in adults. Int J Lab Hematol. 2007 Aug;29(4):261-78. doi: 10.1111/j.1751553X.2007.0093.X.

4. Moureau N, Lamperti M, Kelly LJ, Dawson $R$, Elbarbary $M$, van Boxtel AJ, Pittiruti $M$. Evidence-based consensus on the insertion of central venous access devices: definition of minimal requirements for training. $\mathrm{Br}$ J Anaesth. 2013 Mar;110(3):347-56. doi: 10.1093/bja/aes499.

5. McGee DC, Gould MK. Preventing complications of central venous catheterization. N Engl J Med. 2003 Mar;348(12):1123-33. doi: 10.1056/
NEJMra01183.

6. Graham AS, Ozment C, Tegtmeyer K, Lai S, Braner DA. Central venous catheterization. N Engl J Med. 2007 May;356(21):e21. doi: 10.1056/NEJMvcm055053.

7. American Society of Anesthesiologists Task Force on Central Venous Access, Rupp SM, Apfelbaum JL, Blitt C, Caplan RA, Connis RT, Domino KB, Fleisher LA, Grant S, Mark JB, Morray JP, Nickinovich DG, Tung A. Practice guidelines for central venous access: a report by the American Society of Anesthesiologists Task Force on Central Venous Access. Anesthesiology. 2012 Mar;116(3):539-73. doi: 10.1097/ALN.0b013e31823c9569.

8. O'Grady NP, Alexander M, Burns LA, Dellinger EP, Garland J, Heard SO, Lipsett PA, Masur H, Mermel LA, Pearson ML, Raad II, Randolph AG, Rupp ME, Saint S; Healthcare Infection Control Practices Advisory Committee (HICPAC). Guidelines for the prevention of intravascular catheter-related infections. Clin Infect Dis. 2011 May;52(9):e162-93. doi: $10.1093 / c i d / c i r 257$.

9. Katz D, Goldberg A, Khanal P, Kahol K, DeMaria $S$. Using serious gaming to improve the safety of central venous catheter placement: a post-mortem analysis. IJGCMS. 2014;6(4):34-44. doi: 10.4018/ ijgcms.2014100103.

10.Lorente L, Huidobro MS, Martín MM, Jiménez A, Mora ML. Accidental catheter removal in critically ill patients: a prospective and observational study. Crit Care. 2004 Aug;8(4):R229-33. doi: 10.1186/cc2874.

11.Ullman AJ, Cooke ML, Mitchell $M$, Lin F, New K, Long DA, Mihala G, Rickard CM. Dressings and securement devices for central venous catheters (CVC). Cochrane Database Syst Rev. 2013 Sep;(9):CD010367. doi: 10.1002/14651858.CD010367.pub2.

12.Sundararajan K, Wills S, Chacko B, Kanabar G, O'Connor S, Deane AM. Impact of delirium and suture-less securement on accidental vascular catheter removal in the ICU. Anaesth Intensive Care. 2014 Jul;42(4):4739. PMID: 24967762.

13.Seldinger SI. Catheter replacement of the needle in percutaneous arteriography: a new technique. Acta Radiol Suppl (Stockholm). 2008 Aug;434:47-52. doi: 10.1080/02841850802133386.

14. Webster J, Gillies D, O'Riordan E, Sherriff KL, Rickard CM. Gauze and tape and transparent 
polyurethane dressings for central venous catheters. Cochrane Database Syst Rev. 2011 Nov;(11):CD003827. doi: 10.1002/14651558.CD003827.pub2.

15.Sessler CN, Gosnell MS, Grap MJ, Brophy GM, O'Neal PV, Keane KA, Tesoro EP, Elswick RK. The Richmond Agitation-Sedation Scale: validity and reliability in adult intensive care unit patients. Am J Respir Crit Care Med. 2002 Nov;166(10):1338-44. doi: 10.1164/ rccm.2107138.

16.Ely EW, Margolin R, Francis J, May L, Truman B, Dittus R, Speroff T, Gautam S, Bernard GR, Inouye SK. Evaluation of delirium in critically ill patients: validation of the Confusion Assessment Method for the Intensive Care Unit (CAM-ICU). Crit Care Med. 2001 Jul;29(7):1370-9. PMID: 11445689.

17.Knaus WA, Draper EA, Wagner DP, Zimmerman JE. APACHE II: a severity of disease classification system. Crit Care Med. 1985 Oct;13(10):818-29. PMID: 3928249.

18.McDonald CP, Lowe P, Roy A, Robbins S, Hartley S, Harrison JF, Slopecki A, Verlander $\mathrm{N}$, Barbara JA. Evaluation of donor arm disinfection techniques. Vox Sang. 2001 Apr;80(3):135-41. PMID: 11449952.

19.McDonald C, McGuane S, Thomas J, Hartley S, Robbins S, Roy A, Verlander $\mathrm{N}$, Barbara J. A novel rapid and effective donor arm disinfection method. Transfusion. 2010 Jan;50(1):53-8. doi: 10.1111/j.2995.2009.02332.x.

20.24. MitchellSE, ClarkRA. Finger-trapmethod of suturing biliary drainage catheters to the skin. AJR Am J Roentgenol. 1981;137(3):6288. doi: 10.2214/ajr.137.3.628.

21. Nascimento CC, Toffoletto MC, Gonçalves LA, Freitas Wd, Padilha KG. Indicators of healthcare results: analysis of adverse events during hospital stays. Rev Latinoam Enf. 2008 Jul-Aug;16(4):746-51. doi: http//dx.doi. or/10.1590/S0104-11692008000400015.

22.Bevc S, Pecovnik-Balon B, Ekart R, Hojs R. Non-insertion-related complications of central venous catheterization-temporary vascular access for hemodialysis. Ren Fail. 2007;29(1):91-5. doi: $10.1080 / 08860220601039106$.

23.Jaber S, Chanques G, Altairac C, Sebbane $M$, Vergne $C$, Perrigault PF, Eledjam JJ. A prospective study of agitation in a medicalsurgical ICU: incidence, risk factors, and outcomes. Chest. 2005 Oct;128(4):2749-57. doi: 10.1378/chest.128.4.2749.

24.Frasca D, Dahyot-Fizelier C, Mimoz O. Prevention of central venous catheterrelated infection in the intensive care unit. Crit Care. 2010;14(2):212. doi: 10.1186/ cc8853.

25.Curelaru I, Linder LE, Gustavsson B. Displacement of catheters inserted through internal jugular veins with neck flexion and extension. Intensive Care Med. 1980;6(3):179-83. PMID: 7391346.

26.Pérez-Granda MJ, Guembe $M$, Cruces $R$, Bouza E. Vascular catheter colonization: surveillance based on culture of needleless connectors. Crit Care. 2016 May;20(1):166. doi: 10.1186/s13054-016-1334-1.

\section{Correspondence:}

Ana Beatriz Alkmim Teixeira Loyola

Mestrado Profissional em Ciências Aplicadas à

Saúde, UNIVÁS

Avenida Coronel Alfredo Custódio de Paula, 240

37550-000 Pouso Alegre - MG Brasil

Tel.: (55 35)3449-8772

aloyola@infinitetrans.com

Received: Apr 03, 2017

Review: June 06, 2017

Accepted: July 05, 2017
Conflict of interest: none

Financial source: none

${ }^{1}$ Research performed at Professional Master's Program in Applied Health Sciences, Universidade do Vale do Sapucaí (UNIVÁS), Pouso Alegre-MG, and Division of Plastic Surgery, Department of Surgery, Universidade Federal de São Paulo (UNIFESP), Brazil. Part of Master degree thesis, Professional Master's Program in Applied Health Sciences, UNIVÁS. Tutor: Ana Beatriz Alkmim Teixeira Loyola. 